Marietjie Myburg*

\title{
Media, mediation and the war in Iraq: from broken to non- existent mirrors
}

\begin{abstract}
Media theory, says McQuail (2005:5) is an effort to 'make sense of observed reality'. The 'observed reality' of war is layered with themes of power, politics and culture on several levels. There is the journalist on the beat; the news institution he or she works for; the soldiers or armies involved in the conflict; the governments these armies represent and finally there are the media users on both sides of the conflict - that is if there are only two sides. In this sense war represents a highly concentrated or condensed version of everyday reality which forms the framework for media connecting with society.

This report will take the case of the war in Iraq as an example of how the media's role to ‘sustain a shared sense of social order' (Allan, 2004:8) and to connect us 'to other experience' (McQuail, 2005:83) have been compromised by political, ideological and, on the side of the global media networks, economic agendas.
\end{abstract}

Key words: Broadcasting news channels, communication, compromised, cultural literacy, embedding, hegemony, mediation, reality, sources, war reporting.

* Marietjie Myburg is a Master's student in the Department of Journalism at Stellenbosch University. Contact details: mmyburg@idasa.org.za.

P.O. Box 927, Houghton, 2041. Tel: +27 12 3920500. Fax: +27 866333222 


\section{INTRODUCTION}

The Iraq conflict is the great crisis of our era, but television has found it impossible to cover it properly. The dangers to correspondent and crew are too great, and the limitations of being embedded with the United States or British armies subvert balanced coverage (Cockburn, 2007).

The biggest obstacle to mediation may prove to be the channels of news. For the purpose of this essay the focus on channels will be narrowed to the mainstream broadcasting news channels that employ war reporters and specifically the 24 hour news channels such as CNN, Fox and BBC.

Taking both a critical political economy and normative/functionalist approach the essay will look at the mediation function of the media using as analytical tools the basic concerns of media theory and research but replacing the concept of communication with mediation. Thus: 'Who communicates to whom?' becomes 'Who mediates to whom?'; 'What are the function and the purpose of the communication?' becomes 'What are the function and the purpose of the mediation?'; 'How does the communication take place?' becomes 'How does the mediation take place?'; 'What is the communication about?' becomes 'What is the mediation about?' and 'What are the intended and unintended outcomes of the communication?' becomes 'What are the intended and unintended outcomes of the mediation?'.

Conflict and war have always accentuated the inherent tension and potential dichotomies of the media's role in producing and distributing information to inform 'standards, models and norms' (McQuail, 2005:81). Whose norms, whose models, whose standards? The coverage of the war in Iraq is an example of how the media have compromised their legitimacy on all sides of the political and economic power struggle in service of a hegemonic agenda parading as a worthwhile nationalist and patriotic cause. This essay will show why this choice by Western journalists in general has made it impossible to tell the readers, viewers and listeners what happened, happens or will happen in Iraq and more importantly, who are the people on all sides who are affected.

\section{WAR COVERAGE: THE NATURE OF THE SOURCES AND THE DILEMMAS OF THE RECEIVERS}

Over the years the eye witness report has become the salient feature that gives war reporting credibility and legitimacy. Being at the source and thereby observing first hand gives the war reporter 'discursive authority' (Allen \& Zelizer, 2004:5). (Insert in reference section) Former $B B C$ war correspondent,Kate Adie describes this authority: 'I was there to witness, to repeat what I hear, to observe the circumstances, note the detail, and confirm what is going on with accuracy, honesty and precision' (Adie quoted in Allen \& Zelizer, 2004:5). This, she maintains, is 'the only guarantee you can give your listeners, or viewers, or readers. You are telling the truth as far as you know' (Adie in Allen \& Zelizer, 2004:5).

But telling the truth and bearing witness are not so easily equated. In making choices about sources a journalist has to consider allegiance, responsibility, truth and balance. When these features get mixed up with the issues of patriotism, national identity and cultural politics, 'truth' becomes even more elusive. 
To add further to the complexity media users interpret news from within the framework of their own set of patriotic, nationalist and cultural values and their own sense of what constitutes allegiance, responsibility, truth and balance. 'In large parts of the world, notably the Islamic world, there is a revolt not only against foreign political rule but cultural domination. The foreign media are seen as part of the latter' (Cockburn, 2007). This is almost certainly as a result of political and power relations that are beyond media control but it is also, as certainly, a result of the particular mediation role that Western war reporters assumed in Iraq. The perception of the Islamic world that the media are complicit in the quest for cultural domination could for instance be traced back to the reluctance, mostly informed by concerns of a political economy nature, to ensure a greater variety of sources in telling the story of the war in Iraq to a world that stretched beyond the US boarders.

Acknowledging that war reporting tends to be 'one sided' and generally from the point of view of 'the country in which they (the reporters) and their major owners and readers are based', Boyd-Barrett (2004:29-30) (insert in reference section) describes war reporting in Afghanistan and Iraq as stories told by 'Western correspondents reporting from Western positions speaking to (mainly approved) Western political and military sources, mainly about Western military personnel, strategies, successes and, less often, failures and backed with comments from (often vetted) Western military “experts”'.

And that was, by all accounts, what the home audience expected of the news 'from the front. At the start of the war the ratings of Fox News overtook that of CNN. Their explanation for their popularity was that their pro-war and partisan agenda were more 'in tune' with public opinion than CNN's more 'neutral stance' (Allen \& Zelizer, 2004:6).

In describing a frame of reference for connecting media with society McQuail (2005:84-85) describes a process based on Westley and MacLean's revised 1957transmission model of communication (in McQuail, 2005:84). This model proposes that the media 'provide their audience with a supply of information, images, stories and impressions, sometimes according to anticipated needs, sometimes guided by their own purposes ... and sometimes following the motives of other social institutions ...' This transmission model combined with a number of normative themes provides a theoretical rationale for how reporters sourced and how media users received information on the Iraq war. According to McQuail (2005:42-43) political control over the media is more likely when there is a normative dimension to the output or when 'public interest' is at stake. From the perspective of normative theory, how the media ought to have operated in Iraq took on a dimension of what McQuail (2005:162) later calls 'normative obligation' or 'normative expectation'. In both their relationship with media users and the political powers there were strong signals of 'what they ought to do' as US citizens and patriots.

\section{THE FUNCTION, PURPOSE AND POLITICS OF MEDIATING THE STORY OF A WAR}

If you ask media institutions or journalists about the purpose of war coverage the response would probably be fairly simple: to play the role of what McQuail (2005:322) calls objective reporters and critical observers. Objectivity is a 'theoretically contested' term but it summarises those qualities that 'make for trust and reliability on the part of the news audience' (McQuail, 2005:563). The biggest problem with the pretence of objectivity in the case of the Iraq war is that it ignores 
what Boyd-Barrett (2004:36) calls the 'metanarrative of empire and control' and assumes news provision as neutral and devoid of ideology. Media institutions generally leave reflection on the purpose served by the information they provide to academics. There may be some analysis using aspects of operational theory - that is 'practical ideas assembled and applied by media practitioners in the conduct of their own media work' (McQuail, 2005:15) - but in general reflection processes in newsrooms and editorial offices remain one-dimensional and limited to what is necessary to satisfy internal agendas and goals rather than larger societal concerns. The reflection, for example, of the New York Times in March 2004 on its own coverage of the Iraq war (quoted in McQuail, 2005:323) had some normative rationale but it was mostly based on technical flaws like follow-up, verification of facts and inappropriate placement of corrections to name a few.

For the United States the war in Iraq provided an opportunity to apply and refine lessons in dealing with the media, based on considerations of political economy and learned from the mediation function in previous wars or conflicts. 'Spinning' or propaganda strategies were put in place to achieve their own communication objectives of establishing 'US capitalistic worldwide hegemony (Boyd-Barrett, 2004:36). 'Embedding' was one such strategy.

Although the Pentagon only formally introduced the concept of the 'embedded' reporter in the current war in Iraq (Boyd-Barrett, 2004:30), (insert in reference section) different forms of embedding were tested before. Boyd-Barrett (2004) lists the examples in Grenada, Panama, the Falklands, Afghanistan and the first Gulf War in 1990-1 where officials monopolized and manipulated the media's opportunities for mediation. They limited access to 'sanitized information from official sources', rationed transportation and communication facilities and excluded 'non-approved' journalists from military protection, facilities and press pools. 'Embedding' reporters with the US (read also UK and other allies) military forces in Iraq took the concept to another level. Reporters were attached to armed service units which guaranteed them first hand accounts of 'action'. This offered reporters the first prize in war reporting: the eyewitness account.

As it turned out these 'eyewitness accounts' came at a price. The most obvious price was forfeiting control over content and by implication the first function and purpose of a journalist namely to provide comprehensive, accurate and contextual news coverage. Media users - despite its allegiance, patriotism and nationalism or maybe because of that - instinctively knew they were not getting a good news deal. Patrick Cockburn (2007) says people turned up in great numbers for talks when he publicised his book about the Iraq war. They told him the reason they came to listen to him was 'because they did not feel they were getting the real news about Iraq from television'. Another sacrifice was, oddly enough, the very safety they were guaranteed as part of the embedded pact. 'Iraq has become almost impossible to cover adequately by the old system of foreign correspondents, cameraman or woman, and crew. It is simply too dangerous for a foreigner to move freely around Baghdad and the rest of the country' (Cockburn, 2007). Whatever the function and purpose of reporting in Iraq had before, this purpose became obsolete when the story became 'impossible to cover'.

\section{FOREIGNERS REPORTING FROM A FOREIGN LAND - MEDIATING CHANNELS, LANGUAGE AND TYPES OF INFORMATION}


War reporting is not just about coverage of the warring action. Almost invariably war reporting happens in contexts out of the journalists' national and cultural bounds. This adds to an already complex mix of political, military, economic and cultural limitations.

George Claassen (2001:4) (insert in reference section) explores the challenges in terms of 'cultural literacy' posed by the rise of entertainment as a news commodity. In this sense 'cultural literacy' is used as a 'network of information' that binds 'competent readers' (Hirsch in Claassen, 2001:5). Claassen's (2001:8) premise in this article relates more to the implications for media content in a context of growing ignorance through a 'culture of entertainment', but he touches briefly on the media working in multi-cultural environments. '...Journalists today are more and more forced to work in cultural environments where their own cultural framework of reference lacks certain absolute necessities to be able to report on news (2001:10). This has relevance for the kind of mediation that takes place from the war front to the audience at home.

If journalists are not expected to 'go native' in times of peace, this is an even more relevant expectation in times of war. For the war reporter with the sincere objective to 'observe the circumstances, note the detail, and confirm what is going on with accuracy, honesty and precision' (Adie in Allen \& Zelizer, 2004:5) it is crucial to distinguish between patriotism, militarism and national identity and to explore beyond the limitations of his or her own cultural framework for the full story. The war reporter needs to make a genuine effort to decode the local context as well as the actions of the invaders if they want to connect the audience at home with the experience of others involved in the conflict. Unless this happens, the mediation role of the media as signpost, guide or interpreter who points the way and 'makes sense of what is otherwise puzzling or fragmentary' (McQuail, 2005:83) is eroded.

Another, and perhaps the biggest obstacle to mediation that constructively informs standards, models and norms of all media users, may prove to be the news broadcasting channels. The seduction of massively increased viewing figures in the days following the declaration of conflict in Iraq - CNN figures were up 393 percent and Fox by 379 percent (Allen \& Zelizer, 2004:7) - resulted in what Martin Bell insert in reference section (in Allen \& Zelizer, 2004:11) calls the 'F-words' that define the 24-hour news service: 'first', 'fastest', 'fearful', 'feverish', 'frenzied', 'frantic', 'frail', 'false' and 'fallible'. If before the pressure on the war reporter was in the form of nationalist and patriotic expectations, this added commercial pressure. Viewers quickly became used to and then demanded more 'breaking news' stories. Television became the news source of choice to users at home and to feed the 'hungry' medium editors often sacrificed 'we got it right' for 'we got it first' (Bell in Allen \& Zelizer, 2004:12). This had consequences in terms of the credibility, and subsequently for the usefulness, of the information. It also further reduced the possibility of reflecting voices other than the official ones and of relaying stories other than those of the 'home boys' because these were instantly available and in some cases almost pre-packaged by the Pentagon. Instead of 'extending the vision' (McQuail, 2005: 83) of the audience back home, the war reporters used news that was filtered by the state's spin machinery. In making this mediation choice they closed off other views and voices (McQuail, 2005: 83) and limited the types of information that could and should have formed part of the story.

\section{WHAT IS THE MEDIATION ABOUT - THE CONTENT, REFERENCES AND CODES OF THE WAR IN IRAQ}


The war reporter works in a particular political, cultural, economic and social context and he or she needs to be conscious of this when considering the content of the news reports sent out. What kind of platform for debate does his or her reporting provide for in the political sphere? How does he or she represent or express cultural identity? What material does he or she present for 'forming and maintaining social identity' (McQuail, 2005:4) or 'a shared perception of reality’ (McQuail, 2005:81).

Susan Moeller (2004:60) argues that war reporting is a subset of reporting on international affairs. This also has relevance for the content of war reporting. Instead of just providing information; instead of holding up a mirror, the war reporter will be conscious of the underlying power relations at play. This, at least in the case of Iraq, may seem overwhelmingly complex. Not only is there the obvious power relation between the US and Iraq governments, there are also power relations between the US and its allies and power relations between the Sunnis, Shiites and Kurdish forces inside Iraq. The war reporter will also reflect an awareness of themes of power and effect.

Media users depend on the war reporter to inform them of the 'breaking news' but they also depend on the media's connection to politics to know how they are affected and should relate to the world of politics (Croteau \& Hoynes, 2003:15). Insert in reference section. Providing context for content is a way of emancipating the media user. A deeper understanding of events provides him or her to 'make sense of reality' with more authority.

\section{REPORTING THE WAR IN IRAQ - INTENDED AND UNINTENDED OUTCOMES}

A newspaper headline (Sengupta \& Cockburn, 2007:16) suggests that the war on terror has made the world 'a more terrifying place'. Kim Sengupta and Patrick Cockburn report that the number of deaths from 'jihadist' attacks around the world increased from 729 in the period between September 112001 and the invasion in Iraq, to 5420 in the period since the invasion up to the first quarter of 2007 (Sengupta \& Cockburn, 2007:16). To what extent can the act of war be detached from communicating or reporting on the act? How much of the fact that the world is now 'a more terrifying place' can be attributed to the way in which the media intervened between media users and the 'reality on the ground'? If the media performed their mediation role differently could this outcome have been different?

There is evidence that in the emotional aftermath of $9 / 11$ most US journalists' sense of citizenship and patriotism undermined the norms of journalism practice. Susan Moeller (2004:70) quotes CNN reporter Christiane Amanpour's response to Tina Brown in a 2003 interview on $C N B C$ in response to a question about whether journalists had been limited in what they could cover in the war in Iraq: 'All of the entire body politic in my view, whether it's the administration, the intelligence, the journalists, whoever, did not ask enough questions, for instance about weapons of mass destruction'.

In this way, one could argue, the media created - mediated - a political, economic, cultural and social environment in which divisions became more punctuated and more partisan. Oliver Burkman (insert in reference list) (in Allen \& Zelizer, 2004:6) describes embedding as an 'astounding PR success' for the Pentagon, because, he says, 'reporters use the words "we” and "us" profusely, identifying 
themselves with the military'. They gave up objectivity because they had 'a very personal stake in their unit's success', concludes Burkman.

The most significant outcome of this mediation choice is that today the war is almost impossible for foreign journalists to cover (Cockburn, 2007:16). In this case no news is bad news for ordinary media users or citizens but probably good news for those in political power. Cockburn (2007:16):

One of the infuriating aspects of covering Iraq in the past three years has been to hear the US and British governments claim that there are large parts of Iraq that are at peace and know it is untrue but to prove that they are lying would mean getting oneself killed..

In this way US hegemony goes unchallenged and in this case it may very well be that the media have mediated themselves out of the picture and lost an opportunity to challenge that hegemony.

War reporters in Iraq could have made different mediation choices. Improvements in communications technology have removed some of the physical barriers to multilateral coverage that existed before but, says Boyd-Barrett (2004:29), 'there is little evidence so far of these being seriously put to use by mainstream media for the purposes of achieving greater balance and a broader perspective'. Their choice was for a mediation role in which some information was not explored and not made available. This affected the way their audience understood the nature of the war and the consequences for all its victims.

Moeller (2004:59) adds another dimension to war reporting which could have resulted in a different kind of mediation of the situation in Iraq. She describes reporting as an effort to find ways of making 'the lives of distant strangers of value to us'. This assumes that the war reporter will provide media users with more than just the information that serves US interests and that of its allies. But reporters were embedded with the US forces and not, as Schechter notes, with Iraqi families, humanitarian agencies or anti-war groups (quoted by Boyd-Barrett, 2004:31). Because access to official and vetted sources was so easy and access to other voices so difficult, they failed to describe the lives of ordinary people in Iraq as lives that are as valuable as the lives of the US citizens. If they were more successful in telling the stories of the 'distant strangers' it is not an idealistic view to hold that the world may have been a safer place and the current information hiatus may not have been so easy to uphold.

\section{CONCLUSION}

War coverage illustrates clearly how mediation consists of a complex range of issues best described if we return to Westley and MacLean's revised transmission model (McQuail, 2005:84). This accounts for a more complex chain than Lasswell originally proposed with his model of who says what to whom through what channel and to what effect (McQuail, 2005:69). Westley and MacLean propose a sequence of progression which does not start with the communicator but with events and voices in society. This model acknowledges that the communicator or in this case the reporter's version of events is firstly his or her own account, therefore an account; secondly reporters choose to report on a specific even out of a range of possible events and thirdly that reporters channel or give access to the 'views and choices of those ... who 
want to reach a wider public' and that reporters are responsive to the interests and demands of their audiences (McQuail, 2005:69).

In Iraq reporters were faced with a multi-dimensional event. They had to make mediation choices in terms of sources, content, references and codes based on their own perceived sense of patriotism and national identity within the political, economic, cultural and social landscape of post 9/11. This affected their choices in terms of access to the range of voices, choice of events, the codes, the references and content. In making these choices they were guided by the interests and demands of political power, economic interest and their social relations with the media audience back home. This, at least in part, resulted in the outcome faced by foreign reporters in Iraq today: that the story continues but it has become impossible to cover.

War reporting has always been a 'litmus test' for journalism (Allen \& Zelizer, 2004:3). To retain its authority and its meaning as an act of 'social responsibility' (Allen \& Zelizer, 2004:4), will require a return to what is generally accepted as criteria for good journalism practice during war and conflict situations (Allen \& Zelizer, 2004:4):

To be present enough to respond to what is happening, yet absent enough to stay safe; to be sufficiently authoritative so as to provide reliable information, yet open to cracks and fissures in the complicated truth-claims that unfold; to remain passionate about the undermining of human dignity that accompanies war, yet impartial and distanced enough to see the strategies that attach themselves to circumstances with always more than one side'."

September 11 may have changed a lot of things but it did not change the fact that in order to make sense of an event - in the case of war - people need reliable information. Reliable information is the mirror which reflects to media users their place in the world. When the reflection is distorted or covered up the ability of readers, viewers and listeners to participate in, and feel part of, world events becomes compromised. To sustain, with integrity, the power of ordinary people to contribute and feel part of their immediate, and not so immediate, world is an awesome challenge for journalists and media institutions to return to after the media experience in Iraq.

\section{REFERENCES}

Allan, S. 2004. News culture (Second ed.). Berkshire: Open University Press. Burkman, O

Cockburn, P. 2007. War almost impossible for foreign journalists to cover. The Sunday Independent, 2007-03-04:16.

McQuail, D. 2005. McQuail's mass communication theory. London, Thousand Oaks, New Delhi: Sage Publications.

Moeller, S.D. 2004. A moral imagination - the media's response to the war on terrorism. In S. Allen \& B. Zelizer (eds.), Reporting war - journalism in wartime. 59-76. London, New York: Routledge.

Sengupta, K., \& Cockburn, P. 2007. How the war on terror made the world a more terrifying place. The Sunday Independent, 2007-03-04:16.

Sengupta, K. \& Whitaker, R. 2007. British forces leave behind a bloody battle of

Basra. The Sunday Independent, 2007-03-04:16. 